\title{
The Determination of the Market Value of Works in Progress with Probability Graphs
}

\author{
István Hajnal \\ Department of Construction \\ Management; Faculty of Architecture; \\ Budapest University of Technology and \\ Economics, Budapest, Hungary \\ hajnal@ekt.bme.hu; \\ drhajnali@gmail.hu
}

ONE OF THE MOST APPARENT SIGNS OF THE INTERNATIONAL REAL ESTATE CRISIS IS THE MANY UNFINISHED CONSTRUCTION INVESTMENTS. The various states and professional organizations are attempting to mitigate investment risks with regulations and methodology instructions, and, thus inspiring new confidence, to kick-start financing, which is the engine driving the real estate market. New methods and approaches are necessary in the area of real estate valuation also, to ensure that the market value of works in progress could be accurately determined at all times, thereby facilitating the management of risks and reinforcing the confidence of the investors.

The author of the article reviews and evaluates the methods with which the value of works in progress can be estimated well, and which can replace the static, simplistic approach currently used by appraisers. While comparative methodology is not suitable to tackle the problem,

\section{Keywords}

Real Estate; Probability Graph; Risk Mitigation; Valuation; Work in Progress as the first practical step, in the net replacement cost based valuation approach the Market Value of the land, as value-forming factor, must continuously be examined. The income-based calculation approach can easily be made suitable for the determination of the Market Value of works in progress. If the works are suspended, the author suggests applying calculations with the probability trees as being the most efficient method for estimating the Market Value. 


\section{INTRODUCTION - The Problem}

This article discusses a real estate valuation issue in an area which has not been explored by the relevant - valuation and project management - professional literature, even though the importance of this problem has been accentuated by recent events in the real estate market and the countless unfinished investments ensuing from these market processes. In this article, the author also examines these real estate valuation processes, in order to ensure that the methodology suggestion offered by him is adequately supported. The methodology problem to be solved is the valuation of works in progress, because at present the investors and financers cannot receive an adequate view of the current Market Value of the development while the implementation of the investment is in progress.

Unfinished and incomplete investments resulting from the crisis can be found throughout the world; overgrown yards, empty concrete frames and abandoned cranes evidence the burst of the real estate bubble from India through Turkey to Central Europe. The real estate industry has always been known for its cyclical nature; at times the dynamic of investments is halted, and at times it proceeds to grow. Before the crisis, one of the basic tenets of the real estate market was that, despite the market's cyclical nature, real estate values continuously rise at a rate exceeding the general inflation rate. At the same time, the real estate crisis, which started about seven years ago, has challenged all of the prior set-instone real estate paradigms. In the course of the crisis all of the earlier market topoi have toppled, and we are facing a new, as of yet unknown real estate market. It has also turned out that the demand for real estate use, which continuously grew for decades, after the crisis has not only refused to continue to grow - as a result of the change in the composition of the demographic and, particularly, the spread of information technology - but in fact has been dramatically decreasing. When exploring the reasons for the falling demand, suffice it to refer to the rise of ever more common telework, or the effects of e-commerce, or the decline of the population. As a result, after the crisis a high number of unused properties can be found - office buildings, apartments, small business units. Additionally, oversupply has halted the investors and frozen investments for the long term.

Although it appears that in numerous areas of life the economic crisis is of the past, the real estate indicators apart from a few exceptions - have not been restored; this statement is particularly true about economies where the real estate market is vulnerable, underdeveloped or overheated. For this reason, the attitude and risk management of the financers has fundamentally changed since the crisis. The goal of the various regulations and legal provisions set in place after the crisis is that financing would be confined into the constrains of fairly well estimable risks. Such examples are the regulation system [1] referred to as BASEL III.; the UCITS IV ${ }^{1}$ directive related to collective investments in transferable securities, or the continuously tightening IFRS ${ }^{2}$ regulations, which set forth the norms of international accounting.

Construction loans are still difficult to obtain on the real estate market, due, in addition to the new regulations, to the financers' previous bad experiences and their resulting lack of confidence. One of the bad experiences related to investments is linked to the reliability of real estate valuations.

\footnotetext{
1 DIRECTIVE 2009/65/EC OF THE EUROPEAN PARLIAMENT AND OF THE COUNCIL of 13 July 2009 on the coordination of laws, regulations and administrative provisions relating to undertakings for collective investment in transferable securities (UCITS)

2 IFRS: International Financial Reporting Standards, continually published by the IFRS Foundation
}

For earlier financer practice, presenting the prevailing invested costs was sufficient; real estate appraisers gave an estimate of the prevailing value of construction works in progress with the increasing amounts of the verified expenditures added. For measuring the expenditures, most frequently the $E V A$ (Earned Value Analysis) model, already familiar from Project Management, or a similar approach was used.

The EVA methodology is a wellknown project management tool, which allows the simultaneous measurement of the progress of the project and the performance of the contractor. Numerous professional articles deal with the application and promotion of this method, or provide a comprehensive analysis of it, such as Anbari [2]. However, the EVA approach examines the performance during the construction solely from the aspect of financial/ technical progress, with the planned budget and the planned implementation period being the basis for the calculations. In this examination, the market evaluation of the project, the changes in the market data, and the corresponding prevailing Market Value changes are not included; with the EVA method only a static compliance with a technical condition system can be checked. From the aspect of real estate valuation, the problem with the EVA model is that it does not reflect the changing market conditions, it only takes into account the current expenses.

The everyday practice of real estate valuation treats the EVA methodology loosely: It estimates the financial and, based on that, the technical performance on the valuation date, usually on the basis of the data provided by the investor. The appraiser adjusts the earlier valuation results in light of the newly acquired data; in other words, he or she does not evaluate and qualify market suitability during each re-valuation. Since the basis for the estimated Market Value is set with 
the market environment considered in the original business plan, this is only adjusted with the data related to technical/financial performance due to the construction potentially being protracted to several years. In this way, the Market Value repeatedly redetermined - merely increased by the execution costs - in the course of the implementation of the investment may be misleading during periods of change in the market. In the period before the crisis, this methodology approach posed no problems, since the market and its descriptive indicators continuously grew, therefore the only relevant factor was measuring the progress of the construction.

As a result of the above described appraisal approach, if for any reason the investment is discontinued, its financial records related to the financing value will be erroneous and will result in wrong decisions when used as a basis. During a crisis in confidence, changing the practice and introducing new valuation methods may help restoring confidence.

\section{Discussion}

The value of works in progress In my article, as the first step of examining the problem I wish to clarify what the concept of "value" means. In everyday life, what this term refers to may vary depending on the situation, the context, and the role players. We may talk about value in terms of esthetics, sociology, or in terms of finance. However, even if we remain within the professional area of Project Management, diverse and numerous ways of interpretation present themselves. In their research project of many years, Thomas and Mullaly were attempting to find the general answer to the question of what the value conveyed by Project Management is [3]. Oliomogbe and her fellow author defined value as the aggregate outcome of all of the profit generated for the project participants [4]. Welzl also points out that for companies valuegenerating factors in the changing world are intellectual factors (intangible assets) rather than merely monetary results [5]. The science of value analysis ("value engineering") used in Project Management, and in engineering practice in general, defines value as the ratio of function versus appropriation, thereby materially generalizing the conventional concept of value [6].

In connection with works in progress, the diverse interpretation alternatives of the concept of value similarly arise: We may talk about the usefulness of the investment, its appreciation by the community, its significance for certain participants (e. g. the investor, the financer, or the end users), and so on. At the same time, in connection with the problem proposed in this article - increasing financer confidence - it is useful to confine this concept of diverse meaning to, primarily, the concept of value that can be measured monetarily. Even within the value concept that can be expressed monetarily, we know many forms of value (such as, investment value, loan collateral value, historic value, liquidation value, insurance value, and we could continue listing the various forms of value), but Market Value is almost exclusively used for this kind of evaluation and independent comparison of projects. This form of value is the best solution to ensure that the "value" can be placed with a single variable on a wellinterpretable scale that is commonly known, and can be compared to other alternatives.

\section{Regulating the determination of the Market Value}

A complete and accurate understanding of the concept of Market Value is essential. This concept is widely used in the financial world, but its precise definition is the responsibility of real estate appraisers. Many definitions of the concept are known, and although these correspond, I will quote the most important definitions from both (the financial and appraiser) professional environments. In the accountingfinance environment, and in the world of economic regulations in general, the definition given by the IFRS prevails. As we have indicated in the introduction, based on lessons learned from the world crisis, the experts of the IFRS placed the regulations, including those related to valuation, on new foundations from 2011 [7]. Of the 2014 standards, No. 13 provides a definition of "Fair Market Value." According to this, Fair Market Value is "the price that would be received to sell an asset or paid to transfer a liability in an orderly transaction between market participants at the measurement date." To this definition belongs the presumption that the transaction is taking place on a market where similar assets are in circulation in great numbers, thereby providing a basis and background for the asset valuation. From the aspect of our topic it is important that the explanation of the IFRS's definition determines market suitability according to "Highest and Best Use," and that it classifies the results of valuations depending on data availability - into three risk categories. If the application of the actual market data, without adjustment, is sufficient, then the received results will be appropriately safe during the valuation; however, if they must be applied after adjustment, the value can only be included in "category two." If the input data of the valuation have been based on assumptions, then the received value can only be classified in the high-risk third category. Unfortunately, the usual valuation methods of unfinished investments all work with such methods based on assumptions.

As the top organization of European appraisers, TEGOVA provides the following definition: Market Value is ... "The estimated amount for which the asset should exchange on the valuation 
date between a willing buyer and a willing seller in an arm's length transaction after proper marketing wherein the parties had each acted knowledgeably, prudently and without compulsion." [8]. The authors of TEGOVA have not yet modified the traditional definition and its interpretation as drastically as the creators of the IFRS standard, obviously because the above quoted text is identical with the Market Value definition found in the EU codification (Directive 2006/48/EC relating to the taking up and pursuit of the business of credit institutions). At the same time, the change mentioned in the introduction is clearly demonstrated by the fact that the latest EU directive on home loans also prescribes the observance of the strict asset valuation directives and the risk management of the valuations relevant for the Member States. [9] In its new edition, the "Red Book" of the RICS , which is the earliest and most widely applied real estate valuation standard, aspires to reconcile the above mentioned two approaches the financial and that of the real estate industry - to a common denominator. It is clearly evident that the modification of the directives of real estate valuation, which have been unaltered for decades, has commenced after, and as a result of, the crisis. However, this change has not yet reached everyday methodology and practice; at present, only the clarification and unification of the basic concepts is taking place.

I will briefly summarize the so-called traditional Market Value determination methods generally used on the basis of the above-mentioned standards. No method or algorithm exists for the direct determination of Market Value; three valuation approaches are used in international practice, with the targeted use of which, and by evaluating

3 Royal Institution of Chartered Surveyors, "RICS Red Book," RICS, 2014 the combined results, the appraiser formulates the final market value:

> The comparative market valuation;

> The income-based valuation; and the

Net replacement cost based valuation.

The first method is the comparative market valuation. With this method, appraiser compares the given real estate with other properties that have recently been objects of exchange transactions at known prices and with known parameters. The comparison is made by taking into account buildings, structures, or land lots with identical or similar physical attributes. The known prices of these properties suitable for comparison make up the basic scope of the surveys and analyses we conduct. During the comparative examination, appraiser examines the value-modifying factors that cause deviation from the values of the properties used for the comparison. Using a general formula, the value is generated based on the location and the attributes of the real estate:

$\mathrm{V}=\mathrm{f}(L o c, A t t)$, where

$\mathrm{V}$ : is the market value of the real estate derived from the comparisons,

Loc: is the location value factor and

Att: is the factor of the attributes of the real estate.

Income-based valuation is widely used for the valuation of yield-producing property. Its essence is that the economic indicator (the NPV, Net Present Value) is derived for the property, as a form of investment, from the expectable net revenues from the most economical and best utilization of the real estate, and the cash flow from such revenues. This method is often referred to as the DCF (discounted cash flow) based valuation method. In simpler cases, the yield value can be calculated from direct capitalization, in which case the annual net revenue and the market yield rate ratio provides the approximation to the NPV.
The NPV of the real estate investment - amid balanced market conditions is a very good approximation to the market value of the real estate. It can

$V=\sum_{t=0}^{n} F_{t} \frac{1}{(1+i)^{t}}$, where

be defined by the following formula: $\mathrm{n}$ : is the number of examined periods $i$ : is the market rate taken into account $F_{t}$ : is the net revenue realized in the t period.

The third applicable method approximates the value through the net replacement cost. This method is based on the data related to the construction costs and their changes. The construction cost is derived from the construction industry prices and the additional costs known on the valuation date. The thus determined gross replacement cost must be reduced in proportion with the physical wear and the functional obsolescence of the property. This valuation principle is applicable to built real estate only; the value of the land lot must be determined with one of the two methods described above. The primary reason of obsolescence is time. When estimating obsolescence, the basis must be the economically useful remainder of the life of the real estate; the curve of the depreciation must be estimated as well. It is important that obsolescence is not characteristic of depreciation due to technical reasons only, but to depreciation due to functionality and market conditions also. The following formula can describe this methodology:

$V=G R C-\left(A v_{m}+A v_{f}+A v_{p}\right)+V_{\text {landlot }}$

,where

GRC: is the gross replacement cost of the building,

$A_{v m}$ : is technical obsolescence,

$A_{v f}$ : is functional obsolescence,

$A_{v p}$ : is market obsolescence, and

$\mathrm{V}_{\text {landlot }}$ :is the value of the land lot determined based on the market. 
I would like to emphasize that of the three types of obsolescence the EVA methodology mentioned in the introduction only takes into account technical obsolescence $\left(A_{v m}\right)$, since functional obsolescence is irrelevant while the construction of the project is still in progress. At the same time, the third obsolescence type (market obsolescence, $A_{v p}$ ) is specifically meant to create an indicator that fulfills the definition of Market Value, from the "technical value type" determined on the basis of the technical parameters of the facility.

In addition to the above three methods, the professional literature and, since the 2000's, partly international practice also, use a fourth type of approach as well; this valuation methodology group is usually mentioned under the non-traditional methods group title. In their work published in 2003, Pagourtzi and his associates [10] summarize the methods of real estate valuation. They distinguish the traditional methods discussed in the previous chapters from those they refer to as the "developed" methods. Among these developed methods they count the simulation of artificial neural networks, the hedonic price model, the method of spatial analysis, the fuzzy logic valuation, and ARIMA ${ }^{4}$ modelling. These models are suitable, operating with a high number of samples, to create statistical attributes and use them to determine valuation factors. The large group of non-traditional methods is comprised of the expert systems that provide approximation to the Market Values by the inquiry and analysis either of the data compiled from experts' experience or those of the end users (Contingent Valuation Method).

4 Autoregressive Integrated Moving Average
The market valuation of works in progress

The peculiarities for property construction works in progress, as opposed to the basic principles of Market Value determination, are as follow:

Each real estate is materially different: Construction works in progress are more different from each other than real estates in general. Although, according to the professional axiom, no two properties are the same since each one is situated at a different location, the varying extent of the completeness of real estates in this comparison adds another dimension. Therefore the comparison of these items is even more difficult; practically no two properties can be found that are comparable from a market aspect.

They are not circulating in the market: Unfinished constructions are not typically sold, since the developers know that completed real estates having all of the licenses of the authorities are the sellable (end) products. Although in the wake of the crisis many offers appeared on the market of buildings with only a finished or a just commenced basic structure, such transactions are rare and therefore it is difficult to "price" their market.

They have very detailed technical specifications: In the majority of cases - with the exception of long-discontinued or insolvent projects - the construction plans and design drawings of works in progress are still readily available, as are their cost estimates and quotes, and all of the additional documents of their realization. This information is only partially available in case of the usual real estate market products; the older the completion of the construction is, the less likely it is that its technically relevant information is still accessible for the appraiser. In case of larger projects, the technical content and completeness are continuously monitored, and the technical content is well documented with the use of the EVA methodology, or similar project management tools, throughout all of the stages of the construction. At the same time, in lack of monitoring reports from reliable sources,

their content (completeness, status) can only be determined through considerable technical surveys and analyses: While a completed real estate product can be described briefly and accurately - since it has attributes defined in standards and construction plans -, in case of an unfinished, abandoned construction it is very difficult to know where the implementation is standing on the way toward the finished end product. It is questionable whether the required construction documents are available, whether they accurately reflect the thus far completed work, and whether the completed construction parts have not been damaged since the potential discontinuation of the project. In situations close to bankruptcy, the question arises how the relationship, the financial settling, the construction material orders, and the additional work phases in progress can be closed between the contractor and the developer, and what additional expenditures are needed to resume the construction.

They do not generate revenue: Another valuation problem in case of yield-producing property works in progress is that while a finished product (shopping mall, office building) has known revenue-producing capabilities, which are supported by related previous statements, balance sheets, and contracts, these data are only forthcoming in case of planned investments. It is evidently an advantage that the future incomes of an unfinished investment are partially or completely ensured by an agreement system (e.g. in the form of a pre-lease agreement), these agreements must be renewed when resuming an unfinished, discontinued construction, therefore future revenues can only be defined in estimates.

The projects have no vision: the market quickly changes around the 
unfinished investments. There might be no more demand for the originally planned utilization, or modifications are needed in the interest of the optimal marketability. The already mentioned demographical changes may effect the need for small apartments instead of huge family condominiums that comes along with the change of plans. The re-planning works need severe permission procedure and structural changes. The Highest and Best Use changes time by time. The latter also changes the developer acts that are needed to reach the optimal utilization.

As seen above, in case of works in progress, the comparison of real estates faces many challenges: the properties are not identical, and no market transactions exist in their relevance. Therefore traditional comparative market valuation can essentially be excluded from the potential methods. (Naturally, this statement does not hold true for development lots where construction works have not started yet or only an insignificant amount of work has been completed.)

The method of net replacement cost could basically replace or supplement project analyses conducted with the EVA methodology. For this, the changes in the prevailing land prices should be monitored for works in progress and carried out according to the original schedule, and evaluated with the EVA methodology, and of the abovedescribed three obsolescence items an estimate should be given for market obsolescence. No methodological obstacles exist for the first task, that is, for determination through building lot comparison - or through income approach -; with regard to this matter, only the everyday valuation practice must simply be changed. Considering the fact that, according to experience gained during the crisis, the prevailing value of development lots is very sensitive to changing market conditions, this practical adjustment could result in a material improvement in the reliability of valuations. At the same time, the second task - the determination of market obsolescence - poses a serious methodological problem, since substantial related pre-studies and research would be needed.

If, however, the investment has been discontinued or abandoned, the second obsolescence factor, potentially occurring as a result of the lapse of time - that is, the functional obsolescence factor $\left(\mathrm{Av}_{\mathrm{f}}\right)$ - must also be taken into account. In these cases, the technical status (the technical obsolescence) can only be determined through a detailed survey also. The costs of the repair of potential damages, the examination of the authenticity of the technical documents (in extreme cases, their replacement), and the estimate of the effects of the contractor's miscalculations can only be carried out reliably through material expenditures on expert participation.

Of the traditional methods, the income-based calculation approach promises to be the most suitable for the determination of the Market Value of works in progress. The cash flow built from the combined time series of the costs of completing the project and of the future revenues can be restated or recalculated at any moment during the construction. However, the indication of the quoted regulation of the IRFS must be taken into account here: If all of the input data of a valuation is an estimate, then the result is only suitable to define the Market Price with comments, in a limited manner. For this type of calculation - as opposed to the comparative or the cost-based evaluation - the input data will not be representing market facts, but simply "expectations based on the market facts." The valuation practice of commercial real estate places the greatest emphasis on the valuation approach based on income-based calculation. In case of unfinished investments, it is crucial for the appraiser to repeatedly examine and analyze certain input data of the DCF model during the recurring valuations. Everyday practice considers the variables (rental fees, operating costs, market absorption, yield, etc.) of the Feasibility Study that has approved the investment as constants during the execution phase, and reruns the DCF calculations using only the data of the remaining cost of the construction. However, in case of prolonged constructions, through extremely changeable market conditions, the variables cannot be considered as constants; in fact, the Market Value will significantly fluctuate due to their change through time.

Among the cash flow variables of the income-based calculation, there are such that change in connection with the technical factors of the construction: e. g., the remaining time until completion, or the total cost of the supplementary works; and there are specifically market-related variables, such as the level of the attainable rental fees. These input data can be considered as random variables. In order to be able to create a view of the risks involved with the Market Value, the distribution of these random variables must, or should be, known. With respect to the market variables, the statistical examinations are regularly conducted by the international real estate consultant companies. The network technique uses various assumptions with respect to the distribution of the data related to the construction (see, e.g., in [11]). However, knowledge of the distribution of the input data, unfortunately, is not sufficient in itself. If the random variables are continuous, and their joint distribution function is continuous also, and if the variables are independent, the joint distribution function is the distribution functions of the individual variables multiplied. In such case the appraiser would have an easy job, because they would receive the NVP indicator (calculated from the cash flow) together with its distribution 


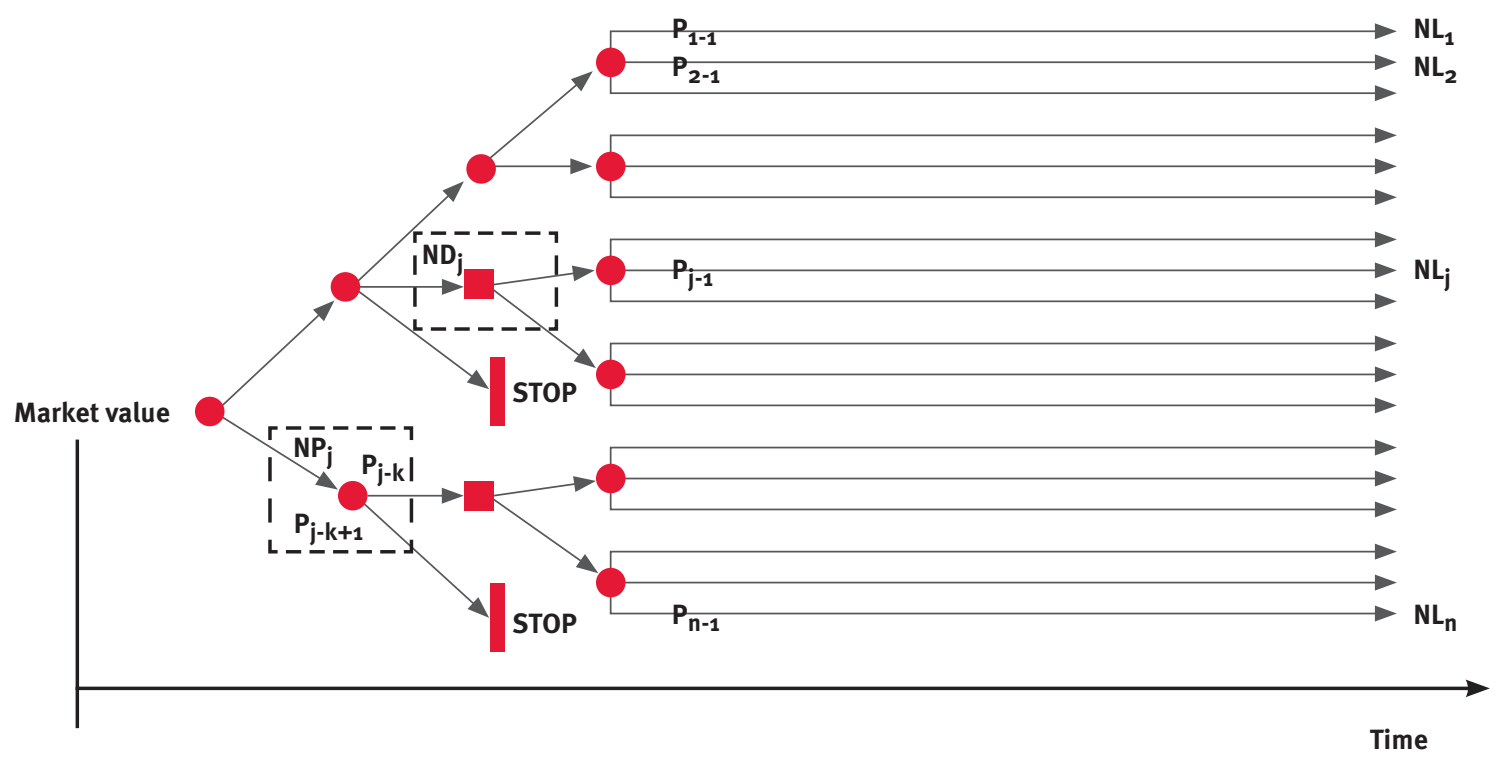

Table 1: Application of probability tree to estimate Market Value

function, from the distribution of the cash flow items. The thus received distribution function would be suitable to describe the current risks of the work in progress. Unfortunately, the variables of the cash flow cannot be considered independent even for the sake of the calculations. And we do not have an appropriate mathematical apparatus available for the analysis of dependent variables [12]. With the use of fuzzy logic, the unique approach of human reasoning and judgment can be integrated into the DCF calculation, for which Hajnal described an application option in his [13] study.

For an approximation, using the above-described view of the random variables, the appraiser practice conducts a so-called "Sensitivity Analysis," in which it calculates the Market Value considering the various potential values of the determining variables, thereby defining Market Value's expected range. If the variables are modelled with discrete values, the application of various simulation methods is possible, such as the Monte Carlo method or probability graphs.

\section{Application of Probability Trees}

The probability trees (in other way, the decision trees) are widely applied in different decision-making analysis (vide f.e. [14]). The point of the construction is that each and every possible vision is marked with one path on a directed tree graph. There are decision nods and probability actions belonging to the path at different moments of time, modeling the financial cash-flow of the path. The leaves of the graph, as the end points of the path can be characterized by the present value of the cashflow. There are three types of nods of the graph: the decision-making nods, where the owner chooses the vision that promises higher present value; the probability nods, where the weighted present value of the upcoming possible visions are presupposed and finally, the nods where the project is stopped by the owner, as - because of the negative present value - there is no sense to continue the investment. The construction is shown at Table No. 1.

The method of calculating the graphs is as follows: the NPV to every single path of directed tree graph can be calculated by the formula (2) presented when the income based valuation was discussed. We order these $\mathrm{NL}_{\mathrm{j}}$ values to the leaves of the graph. Calculations are made backwards from now on along the different paths. In the decision nods (at the ND point of Table No. 1, for example), the value belonging to the $N D_{j}$ nod is the maximum of the previous nod value.

Value $=(\mathrm{NDj})=M A X$ Value $(\mathrm{Ni})$

, where

$\mathrm{N}_{\mathrm{i}}$ is the symbol of the previous nods.

In the probability nod (at the NP point of Table No. 1, for example), the Market Value belonging to the $\mathrm{NP}_{\mathrm{j}}$ nod is the probability-weighted average of previous nod values.

Value $=\left(N p_{j}\right)=\Sigma_{i=j+1}^{J+k} P_{i}^{\star}$ Value $\left(N_{i}\right)$

where

i means the edges of the nod,

$P_{i}$ is the discrete probability of the certain edges and

$\mathrm{N}_{\mathrm{i}}$ is the marking of previous nods. of course, present value can be calculated to the 'STOP' points as well, indicating the expected exit value or the loss to be recognized for the owner. 
By the described backwards calculation method, the Market Value belonging to the starting nod can be calculated, which contains all possible visions with all allocated possibilities.

Let me highlight the application of the method through a simple case to value unfinished investments. Let us value a residential development that had been structurally completed and later - because of the crisis - had been stopped. The building contractors have left the site while there are more interested potential buyers who trust in the warming real estate market. What is therefore the Market Value of this project?

There are more possible visions of the unfinished project. Due to the changes of demands, the previously planned apartments have to be replanned, the building has to meet new requirements during the permission procedure. In a simpler procedure, only the layouts of the apartments are changed. During a comprehensive restructuring, the whole concept of the residential development can be changed. Depending on the contents and the time of new authorization plans, the owner may count with different costs and income. Naturally, it is also possible that the project is finished according to the original plans, as well as that the structure is demolished and the empty plot is used again, in another way. The below Table No. 2. indicates the decision tree constructed based on the above described possibilities.

On the decision tree, there are 11 visions, meaning there are 11 cashflows with values NL1 ... NL11. Of course as many further decision and possibility nods can be put in to modify or to modulate the visions of the project. By the backwards calculating described above, the owner may get the Market Value that integrates all visions of the unfinished investment and may consider all uncertainties and risks of the project.

The above model is specifically suitable to estimate Market Value of unfinished investments because:

it is able to integrate different visions;

it is able to dynamically follow the changes of the market and of the project;

> considers not only the possibilities but also the market based decisions of investors; easily programmed therefore, the appraiser has to reconsider the variables only;

and finally, because of the above, it provides correct answers to the problems of the valuation of unfinished investments presented in the first part of this article.

\section{Conclusion}

Valuation of the stopped, unfinished investments shortly after the real estate crisis is yet an unsolved appraisal problem. In this article, the author has pointed out the mistakes and problems of the present practice and found that there are certain solutions among the tools of the appraisers that can be used to estimate the Market Value of the unfinished investments. Among these solutions, the calculations with the probability graphs are outstandingly significant because different visions may be understood together while the unfinished investment is still described with one number, it is described with the Market Value. As a direction of further research works, we suggest to explore the suitability of additional tools of market appraisers in detail.

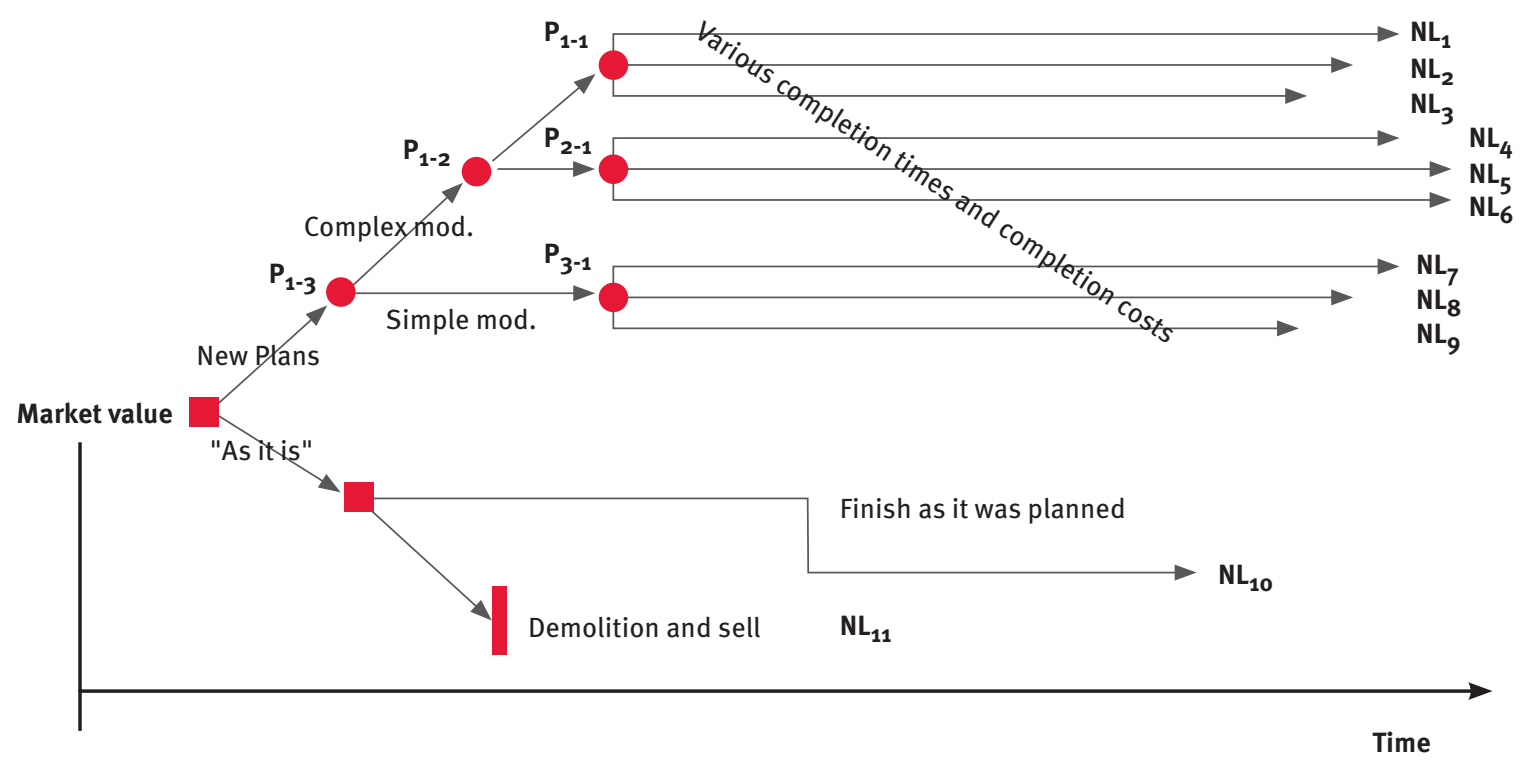

Table 2: A sample on a decision tree 


\section{References}

[1] "Group of Governors and Heads of Supervision announces higher global minimum capital standards". Basel Committee on Banking Supervision. 12 September 2010. (Accessed 28.08.2014)

[2] Anbari, F., 2003, Earned Value Project Management Methods and Extensions, Project Management Journal; Vol 34, No 4. pp 12-23

[3] Thomas, J., Mullaly, M., 2007, Understanding the Value of Project Management: First Steps on an International Investigation is Search of Value, Project Management Journal, Vol. 38. No. 3. pp 74-89, DOI: 10.1002/pmj

[4] Gloria O. Oliomogbe, Nigel J. Smith, 2012, Value in Megaprojects; Organization, Technology and Management in Construction; Vol 4 (3) 2012, pp 617-624, DOI: $10.5592 /$ otmcj2012.3.5

[5] Welzl, G. A., 2011, Values with Meaning Towards reporting of the 21st century, 18th International XBRL Conference

[6] Value Methodology Standard and Body of Knowledge, 2007, SAVE International Value Standard, 2007 edition

[7] IFRS Global Office; 2011; IASB issues new standard on fair value measurement and disclosure. IFRS in Focus, http://www. iasplus.com/en/publications/global/ifrs-infocus/2011/ifrs-13, (Accessed 30.09.2014)

[8] "TEGOVA European Valuation Standards", 'Standard', TEGOVA, 2013

[9] DIRECTIVE 2014/17/EU OF THE EUROPEAN PARLIAMENT AND OF THE COUNCIL of 4 February 2014 on credit agreements for consumers relating to residential immovable property and amending Directives 2008/48/ EC and 2013/36/EU and Regulation (EU) No $1093 / 2010$
[10] Pagourtzi, E., Assimakopoulos, V. Hatzichristos, T., French, N., 2003, Real estate appraisal: A review of Valuation Methods Journal of Property Investment \& Finance, Vol 21, No 4. pp 383-401

[11] Hajdu, M. 1997., Network Scheduling Techniques for Construction Project Management. Kluwer Academic Publishers, ISBN:0-7923-4309-3

[12] Hajnal, I. 1995., Real Estate Appraisal in Hungary, Budapest, BME Mérnöktovábbképző Intézet, ISBN:9634317928

[13] Hajnal, I. 2014., Continuous Valuation Model for Work-in-progress Investments with Fuzzy Logic Method In: Miklós Hajdu, Miroslaw J Skibniewski (ed.) PROCEEDINGS of the Creative Construction Conference, Prague, pp. 206-211 (ISBN:978-963-269-434-4)

[14] Thuesen, G. J., Fabryczky, W. J. 1989,: Engineering Economy, Seventh edition, Prentice Hall, London, ISBN: 013277450 